\title{
Research and practice of teaching quality evaluation system based on the method of system engineering
}

\author{
Han Xianlong \\ Engineering Training Center, Beihua University, Jilin, 132021, China \\ Email: bhhxl@126.com
}

Keywords: Engineering technology; Practice teaching; Quality evaluation; System engineering method

\begin{abstract}
Engineering practice teaching quality is related to many factors, through the systematic analysis of the various aspects of engineering practice in the teaching process and by using the system engineering method to establish the engineering teaching quality evaluation model,proved that the evaluation model is scientific and practical.
\end{abstract}

\section{Introduction}

The higher engineering education is the practical application of engineering, the training will be good at science and technology into productive forces as the goal of engineers. In 2010, the country put forward the "excellent engineer" implementation of the strategic plan, engineering practice teaching is the key to achieve this goal, to improve the students' practical ability and innovation ability is the ultimate goal.. Therefore, further strengthen the construction of teaching quality evaluation system for engineering practice, so as to guide the engineering practice teaching reform, comprehensively enhance the quality of teaching practice of Engineering technology.

Engineering practice teaching is different from the experimental teaching, it is based on professional knowledge, enrich students' knowledge structure optimization, enhance practical ability, cultivate innovative thinking as the ultimate goal. At present, teaching quality evaluation of engineering practice is mainly referring to the experimental teaching evaluation system, so the evaluation result has certain limitations.

This paper uses the method of systematic engineering analysis of the whole process of engineering practice teaching, the factors affecting the quality of teaching combing, combined with the investigation and experiment, establish the teaching quality evaluation model of three layers of engineering practice, the model is solved by the AHP and Fuzzy system tools, quantitative evaluation system, practice has proved that the method is very practical.

\section{Engineering practice teaching quality evaluation index system design}

First, using the 1-9 scale method is put forward by Professor Saaty of the United States operational research experts, different evaluation index comparison judgment matrix;Second, for judging the eigenvalues of the matrix,to find the largest eigenvalue $\lambda_{\max }$ and the feature vector $\mathrm{W}$; finally the judgment matrix consistency test with Saaty average random consistency index, and the calculation process is as follows:

(1) first, to determine each column element matrix is normalized, the elements of the general term for:

$$
\bar{P}_{i j}=\frac{P_{i j}}{\sum_{k=1}^{n} \overline{P_{i j}}} \quad(i, j=1,2,3, \cdots, \mathrm{n})
$$

(2)the judgment matrix of each column normalized by row sum

$$
\bar{W}=\sum_{k=1}^{n} \overline{P_{i j}} \quad(i, j=1,2,3, \cdots, \mathrm{n})
$$


Table 1 engineering practice teaching quality evaluation system

\begin{tabular}{|c|c|c|}
\hline $\begin{array}{l}\text { Target layer } \\
\text { A }\end{array}$ & Rule layerB & Measure layer C \\
\hline \multirow{19}{*}{$\begin{array}{l}\text { The quality } \\
\text { evaluation } \\
\text { of practice } \\
\text { teaching }\end{array}$} & \multirow{3}{*}{$\begin{array}{l}\text { teaching system } \\
\qquad \text { B1 }\end{array}$} & The fit of the school personnel training mode C11 \\
\hline & & $\begin{array}{l}\text { The consistency of training objectives and professional training } \\
\text { project C12 }\end{array}$ \\
\hline & & Practice teaching and theory teaching mutual penetration C13 \\
\hline & \multirow{3}{*}{ Teaching FilesB2 } & The training plan, outline, task, complete instructionsC21 \\
\hline & & The outline of the complete training project C22 \\
\hline & & Engineering practice teaching quality evaluation standard C23 \\
\hline & \multirow{3}{*}{$\begin{array}{l}\text { The } \\
\text { implementation of } \\
\text { teaching } \\
\text { B3 }\end{array}$} & $\begin{array}{l}\text { Technology and skills training projects have specific standards } \\
\text { and requirements and implementation details C31 }\end{array}$ \\
\hline & & $\begin{array}{l}\text { The training project in technology and skills training } \\
\text { examination and assessment in strict accordance with the } \\
\text { provisions C32 }\end{array}$ \\
\hline & & Teaching personnel training with clear responsibilities C33 \\
\hline & \multirow{3}{*}{$\begin{array}{l}\text { Teaching guide } \\
\text { B4 }\end{array}$} & $\begin{array}{l}\text { The training project clearly, safety education in place, the } \\
\text { content is clear and prompt, appropriate training C41 }\end{array}$ \\
\hline & & $\begin{array}{l}\text { Operating norms, accurate and skilled, skilled, diverse forms of } \\
\text { flexible, proper methods C42 }\end{array}$ \\
\hline & & Tour guide, patient and meticulous C43 \\
\hline & \multirow{4}{*}{$\begin{array}{l}\text { Teaching } \\
\text { Feedback } \\
\quad \text { B5 }\end{array}$} & $\begin{array}{l}\text { Complete the training project on time, skilled operation, } \\
\text { complete specification training report C51 }\end{array}$ \\
\hline & & Most of the students skills to achieve a good standard C52 \\
\hline & & $\begin{array}{l}\text { Most of the students can make comprehensive use of } \\
\text { technology to solve the major practical problems C53 }\end{array}$ \\
\hline & & $\begin{array}{l}\text { Most of the students can master the technology and processing } \\
\text { methods, the equipment of machining process C } 54\end{array}$ \\
\hline & \multirow{3}{*}{$\begin{array}{l}\text { Teaching } \\
\text { FeedbackB6 }\end{array}$} & The students to practice the teaching feedback B61 \\
\hline & & $\begin{array}{l}\text { To carry out scientific research, technical services and social } \\
\text { occupation training effectiveness B62 }\end{array}$ \\
\hline & & $\begin{array}{l}\text { Feedback from employers to the graduates' practical ability } \\
\text { B63 }\end{array}$ \\
\hline
\end{tabular}

(3)The normalized vector

$$
\begin{aligned}
& \bar{W}=\left[\overline{W_{1}}, \overline{W_{2}}, \cdots, \overline{W_{n}}\right]^{T} \\
& \bar{W}_{i}=\frac{\bar{W}_{i}}{\sum_{i=1}^{n} \overline{W_{j}}} \quad(i, j=1,2,3, \cdots, \mathrm{n}), \bar{W}=\left[\overline{W_{1}}, \overline{W_{2}}, \cdots, \overline{W_{n}}\right]^{T} \text { is the eigenvector. }
\end{aligned}
$$

(4)The largest eigenvalue calculation of judgment matrix

$\lambda_{\max }=\sum_{i=1}^{n} \frac{(P W)_{i}}{n W_{i}}(P W)_{i}$ is $P W$ i Component element.

(5)Consistency check: : Calculation of consistency index $C I=\frac{\lambda_{\max }-n}{n-1}$, Calculation of random consistency index $C R=C I / R I, C R$ is Smaller, the better consistency of judgment matrix, it is usually considered that when $C R<0.1$, To satisfy the judgment matrix consistency test; otherwise, should adjust the judgment matrix.

According to AHP method, the index weight to table 2- table 8. 
Table2 Practice teaching quality evaluation A judgment matrix

\begin{tabular}{ccccccccc}
\hline A & B1 & B2 & B3 & B4 & B5 & B6 & weight $_{W_{A}}$ & Consistency test \\
\hline B1 & 1 & 2 & 3 & 4 & 5 & 5 & 0.342 & \\
B2 & $1 / 2$ & 1 & 2 & 3 & 4 & 4 & 0.223 & $\lambda_{\text {MAX }}=6.361$ \\
B3 & $1 / 3$ & $1 / 2$ & 1 & 2 & 3 & 3 & 0.142 & $C I=0.072$ \\
B4 & $1 / 4$ & $1 / 3$ & $1 / 2$ & 1 & 2 & 2 & 0.183 & $C R=0.058<0.1$ \\
B5 & $1 / 5$ & $1 / 4$ & $1 / 3$ & $1 / 2$ & 1 & 2 & 0.062 & \\
B6 & $1 / 5$ & $1 / 4$ & $1 / 3$ & $1 / 2$ & $1 / 2$ & 1 & 0.048 \\
\hline \multicolumn{8}{c}{ Table3 The teaching system of B1 judgment matrix } \\
\hline C1 & C11 & C12 & C13 & weight $_{W_{C 1}}$ & \multicolumn{2}{c}{ Consistency test } \\
\hline C11 & 1 & 2 & 3 & 0.539 & $\lambda_{\text {MAX }}=3.009$ \\
C12 & $1 / 2$ & 1 & 2 & 0.297 & $C I=0.005$ \\
C13 & $1 / 3$ & $1 / 2$ & 1 & 0.164 & \multicolumn{2}{c}{$C R=0.009<0.1$} \\
\hline
\end{tabular}

Table4 The teaching file B2 judgment matrix

\begin{tabular}{cccccc}
\hline C2 & C21 & C22 & C23 & weight $_{W_{C 2}}$ & Consistency test \\
\hline C21 & 1 & 3 & 5 & 0.637 & $\lambda_{\text {MAX }}=3.039$ \\
C22 & $1 / 3$ & 1 & 3 & 0.258 & $C I=0.019$ \\
C23 & $1 / 5$ & $1 / 3$ & 1 & 0.105 & $C R=0.033<0.1$ \\
\hline
\end{tabular}

Table5 The implementation of teaching B3 judgment matrix

\begin{tabular}{cccccc}
\hline C3 & C31 & C32 & C33 & weight $_{W_{C 3}}$ & Consistency test \\
\hline C31 & 1 & 2 & 3 & 0.539 & $\lambda_{\text {MAX }}=3.009$ \\
C32 & $1 / 2$ & 1 & 2 & 0.293 & $C I=0.005$ \\
C33 & $1 / 3$ & $1 / 2$ & 1 & 0.164 & $C R=0.009<0.1$ \\
\hline
\end{tabular}

Table6 Teaching guideB4Judgment matrix

\begin{tabular}{cccccc}
\hline C4 & C41 & C42 & C43 & weight $_{W_{C 4}}$ & Consistency test \\
\hline C41 & 1 & $1 / 2$ & $1 / 4$ & 0.137 & $\lambda_{\text {MAX }}=3.039$ \\
C42 & 2 & 1 & $1 / 3$ & 0.283 & $C I=0.019$ \\
C43 & 4 & 3 & 1 & 0.625 & $C R=0.033<0.1$ \\
\hline
\end{tabular}

Table7 teaching effectivenessB5Judgment matrix

\begin{tabular}{ccccccc}
\hline C5 & C51 & C52 & C53 & C54 & weight $_{W_{C 5}}$ & Consistency test \\
\hline C51 & 1 & 2 & 3 & 5 & 0.483 & $\lambda_{\text {MAX }}=4.019$ \\
C52 & $1 / 2$ & 1 & 2 & 3 & 0.272 & CI $=0.006$ \\
C53 & $1 / 3$ & $1 / 2$ & 1 & 2 & 0.157 & CR $=0.006<0.1$ \\
C54 & $1 / 5$ & $1 / 3$ & $1 / 2$ & 1 & 0.088 & \\
\hline
\end{tabular}

Table8 Teaching FeedbackB6Judgment matrix

\begin{tabular}{cccccc}
\hline C6 & C61 & C62 & C63 & weight $_{W_{C 4}}$ & Consistency test \\
\hline C61 & 1 & 3 & 5 & 0.637 & $\lambda_{\text {MAX }}=3.039$ \\
C62 & $1 / 3$ & 1 & 3 & 0.258 & $C I=0.019$ \\
C63 & $1 / 5$ & $1 / 3$ & 1 & 0.105 & $C R=0.033<0.1$ \\
\hline
\end{tabular}

\section{The mathematical evaluation of Fuzzy data processing}

Fuzzy have the factor set, evaluation set and fuzzy relation matrix, according to the teaching quality evaluation index system of the engineering technique training, the quantitative evaluation of discipline fuzzy comprehensive evaluation method, a layer of factor set down $\operatorname{as}_{U_{B 1}}=\left\{U_{C 11}, U_{C 12}, U_{C 13}\right\}$, other factors set $U_{B 2} 、 U_{B 3} 、 U_{B 4} 、 U_{B 5} 、 U_{B 6}$ similar, the two layer factor set down

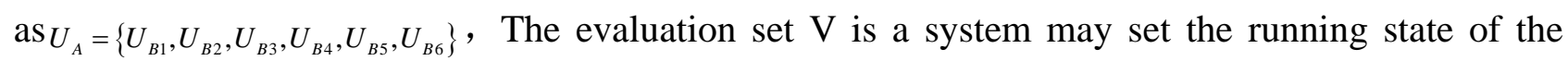
teaching evaluation grade set $V_{1}=\left\{V_{1}, V_{2}, V_{3}, V_{4}, V_{5}\right\}$ Research results indicate that if the rates of excellence, 
good, middle, pass, and fail ,according to the factor set and evaluation set $U$ fuzzy relation between the presence of V,to establish the model of relation matrix $\mathrm{R}, \quad(U, V, R)$ Fuzzy evaluation model is composed of three elements, enter a power allocation vector $\mathrm{W}$, then the evaluation results, the comprehensive evaluation scores.

(1) according to the evaluation system and evaluation indexes of the quality of teaching, by the enterprise experts 3 people, 5 professional leaders, the teaching management staff of 5 people, students fill out the questionnaire of teaching quality engineering practice on behalf of 10 people, the statistics of each evaluation index in the evaluation of the number of $U$ grade $V$, and then normalized, as a result of membership in the evaluation level, the fuzzy evaluation matrix. Table 9 is the statistical results of 13 level of machinery, table 9 data were normalized, the results are as follows:

Table9 Single factor statistical engineering practice teaching

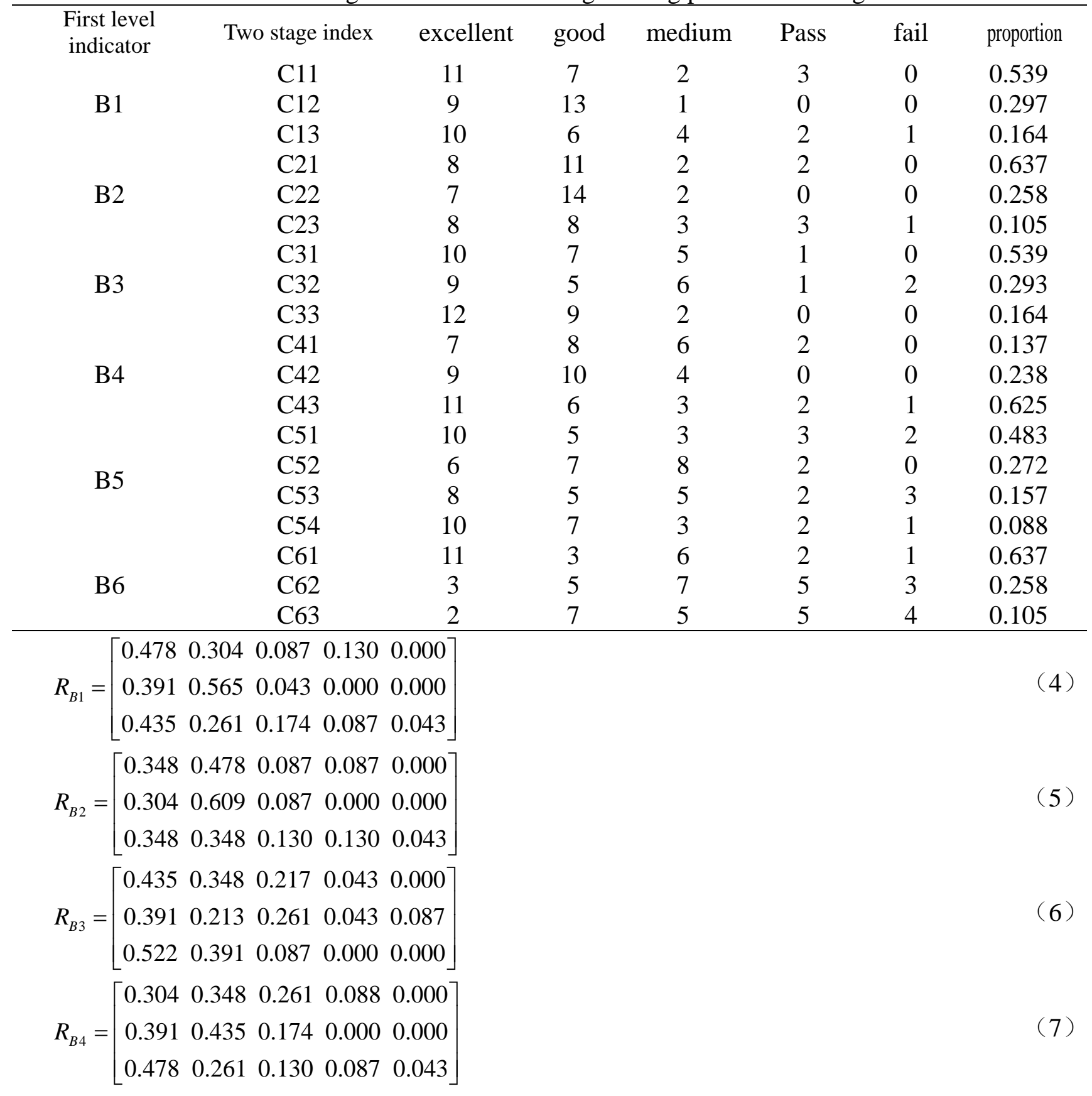




$$
\begin{aligned}
R_{B 5} & =\left[\begin{array}{lllll}
0.435 & 0.217 & 0.130 & 0.130 & 0.087 \\
0.216 & 0.304 & 0.348 & 0.087 & 0.000 \\
0.348 & 0.217 & 0.217 & 0.087 & 0.130 \\
0.435 & 0.304 & 0.130 & 0.087 & 0.043
\end{array}\right] \\
R_{B 6} & =\left[\begin{array}{lllll}
0.478 & 0.130 & 0.261 & 0.087 & 0.043 \\
0.130 & 0.217 & 0.304 & 0.217 & 0.130 \\
0.087 & 0.304 & 0.217 & 0.217 & 0.174
\end{array}\right]
\end{aligned}
$$

(2)The first-level evaluate .The factor matrixRB1The input weights determined by AHP method $W_{C 1}, Z_{B 1}=W_{C 1}, R_{B 1}$, so:

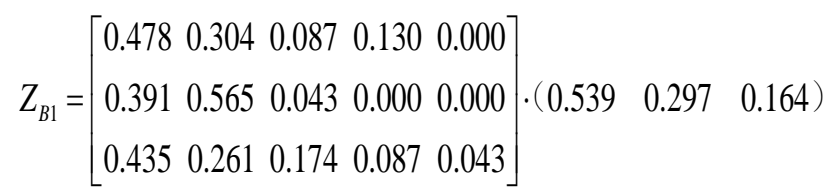

After normalization,

$$
Z_{B 1}=\left(\begin{array}{lllll}
0.475 & 0.401 & 0.095 & 0.022 & 0.007
\end{array}\right)
$$

Similarly available:

$$
\begin{aligned}
& Z_{B 2}=\left(\begin{array}{lllll}
0.342 & 0.505 & 0.091 & 0.057 & 0.005
\end{array}\right) \\
& Z_{B 3}=\left(\begin{array}{lllll}
0.410 & 0.317 & 0.211 & 0.037 & 0.026
\end{array}\right) \\
& Z_{B 4}=\left(\begin{array}{lllll}
0.437 & 0.317 & 0.153 & 0.066 & 0.027
\end{array}\right) \\
& Z_{B 5}=\left(\begin{array}{lllll}
0.370 & 0.244 & 0.207 & 0.111 & 0.067
\end{array}\right) \\
& Z_{B 6}=\left(\begin{array}{lllll}
0.348 & 0.171 & 0.268 & 0.134 & 0.079
\end{array}\right)
\end{aligned}
$$

(3)The comprehensive evaluation of two level。Get a grade evaluation evaluation vector $Z B i$ two grade evaluation matrix $R A$.

$$
R_{A}=\left[\begin{array}{lllll}
0.475 & 0.401 & 0.095 & 0.022 & 0.007 \\
0.342 & 0.505 & 0.091 & 0.057 & 0.005 \\
0.410 & 0.317 & 0.211 & 0.037 & 0.026 \\
0.437 & 0.317 & 0.153 & 0.066 & 0.027 \\
0.370 & 0.244 & 0.207 & 0.111 & 0.067 \\
0.348 & 0.171 & 0.268 & 0.134 & 0.079
\end{array}\right]
$$

$Z=W_{A} \cdot R_{A}$, normalized,

$$
Z=\left(\begin{array}{lllll}
0.416 & 0.376 & 0.136 & 0.051 & 0.02
\end{array}\right)
$$

(4)The comprehensive evaluation score calculation. For each grade assignment by weighted average method, the matrix of each grade after the assignment of the $\mathrm{V}$ :

$$
\begin{aligned}
& V=\left[\begin{array}{l}
95 \\
85 \\
75 \\
65 \\
55
\end{array}\right] \\
&\left.\begin{array}{rl}
D=Z V= \\
0.416 \quad 0.376 \quad 0.136 \quad 0.051 \quad 0.02
\end{array}\right) \cdot\left[\begin{array}{l}
95 \\
85 \\
75 \\
65 \\
55
\end{array}\right] \\
&= 0.416 * 95+0.376 * 85+0.136 * 75+0.051 * 65 \\
&+0.02 * 55 \\
&= 86
\end{aligned}
$$


The calculated value of 86 points, the practical teaching of the comprehensive evaluation of 86 points, 85 points $<86$ points, close to the level of "excellent" etc.

\section{Acknowledgements}

This work was financially supported by Beihua University education reform project (XJZD2016017) and Jilin Province Education Science Planning Project (ZD16017).

\section{Reference}

[1] Bergin M .2011, "N Vivo 8 and Consistency in Data Analysis: Reflecting on The Use of A Qualitative Data Analysis Program” ,Nm se Researcher, Volume18,Number 3,PP 6-12.

[2] Elaime Welsh,2002,"Dealing with Data:Using N Vivo in the QualitativeData Analusis Process”.FOR UM: Qualitative Social Research,Volume 3,Number 2 Art .26.

[3] Huang Guanhong, 6. System engineering method and application [M]. Guangzhou: Jinan University press, 2005.

[4] Wu steel. Modern education evaluation based on [M]. Shanghai: Science Press, 2004.

[5] Zhao Huanchen. A simple and easy method for decision making in analytic hierarchy process [M]. Beijing: Science Press, 1986. 